The Open Electrical \& Electronic
Engineering Journal
Conssmark
Content list available at: www.benthamopen.com/TOEEJ/
DOI: $10.2174 / 1874129001610010027$

\title{
Research of the Inverter Control Strategy Based on the Ant Colony Algorithm and the Fuzzy Control Method
}

\author{
Ren Xian \\ Shanxi Vocational and Technical College of Electric Power, Taiyuan, 030021, China
}

Received: February 22, 2015

Revised: March 20, 2015

Accepted: April 22, 2015

\begin{abstract}
This paper proposes a hybrid control strategy of single-phase inverter, and it makes combination the fuzzy control technology and instantaneous feedback control technology of the current, and it solves the problem of load uncertainty and load model is difficult to established. Through ant colony optimization algorithm the problem that control parameters to solve the problem of the fuzzy control are depended on expert experience is solved. And on the basis of fuzzy voltage outer, the loop current inner loop is added, and through using current loop, it can effectively restrain the load disturbance, current limiting step in the current inner ring at the same time, thus it solve the inverter power supply for impact load adaptability. It not only can make the inverter power supply system output high quality steady-state voltage waveform, but also it can get fast dynamic response. Finally under the environment of Matlab simulation, the simulation results are demonstrated, the feasibility and effectiveness of the proposed compound control strategy are also verfied.
\end{abstract}

Keywords: Ant colony optimization algorithm, Fuszzy control, Inverter power supply, Inverter control, Load adaptability.

\section{INTRODUCTION}

The presence of the nonlinear load and the uncertainties of load change lead to uncertainty the running parameters and variables in inverter power supply, it is difficult to establish accurate mathematical model of the control process of the system, and it has brought a lot of technical difficulties.

In this case, the traditional control theory, such as digital PID control, non-beat control, state feedback control and repetitive control, sliding mode variable structure control, because they both depend on the precise mathematical model of the system for some certainty load has a good control effect, but as for the uncertain or strongly nonlinear load, impact load, the control effect is not ideal, and also has relatively poor adaptability and flexibility, it is difficult to achieve the expected control effect.

Fuzzy control is not focused on the research of the controlled object or its process, but it is based on the artificial experience to imitate the fuzzy concept and control strategy in control activities of human. The complex mathematical modeling can be ignored, through fuzzy subset to construct the membership function for the information obtained, and according to the control rules and reasoning rule it can get fuzzy decision-making, so as to realize effective control of the controlled objects. Therefore the fuzzy control is not sensitive to system parameter variations and external disturbance, which has very strong robustness and can effective control of inverter power supply. In the paper [1, 2], it studied the fuzzy algorithm of the multiple input and multiple output variables, and through using fuzzy control technology to control digital pulse inverter welding power source, and through the control, the welding effect of welding inverter power source has been greatly improved. In the [3] it uses the adaptive coefficient to change the fuzzy control rules, which is applicated in the inverter type resistance spot welding power. In the paper [4], it adjusts PID controller with the fuzzy adjust, fuzzy PID controller is applied to the control of inverter power supply, and the effect of

\footnotetext{
"Address correspondence to this author at the Shanxi Vocational and Technical College of Electric Power, Taiyuan, 030021, China; E-mail: renxian_2014@163.com
} 
controlling of nonlinear load is also good.

Because quantitative level and the fuzzy rules of fuzzy variable in the fuzzy controller are subject to a certain limitation, the precision of fuzzy controller is not very accurate. As to the inverter power, it needs the high quality output voltage waveform of steady state, high accuracy, good dynamic performance and good load adaptability, but it is often difficult to meet these requirements through a single control strategy. In order to meet the points mentioned above, it should use composite control technology [5,6]. Ant colony optimization (Ant Colony Optimization-ACO) algorithm is a novel optimization method imitating natural biological system, which inspired by the foraging behavior of real ants in nature mimic natural biological system, which belongs to the random search algorithm. Through careful observation and the study, the biomimetics find that the ants transmits information between individuals by one kind of material which is called pheromone. In the process of movement, the ants are able to leave the material on the route in its direction of movement, and the ants tend to move in the direction of the material with high strength. herefore, the collective behavior of the ant composed of a large number of ants showed an information positive feedback phenomenon, namely that the more ants is through one path, the greater probability will be for late-comers to choose. The ant is through the information exchange to achieve the purpose of looking for food between individuals. Ant colony algorithm is simulated such optimization mechanism, that is finding the optimal solution through individual information exchange and cooperation $[7,8]$.

\section{Basic Idea of Compound Control}

In the paper, it adopts the method of ant colony algorithm combining with fuzzy control, using ant colony algorithm to optimize the parameters of the fuzzy control system, in order to improve the fuzzy control accuracy and system control performance. But a single fuzzy control can not achieve the purpose of any load has a good effect in this article, such as impact load with instantaneous large current. Due to the current limiting function in the current inner ring voltage outer loop control system is easy to implement, it need only add a limiter at the given value in the inner ring. As for voltage type double closed loop control of three-phase inverter output voltage distortion under nonlinear load is bigger, in the paper [9] it proposes capacitive current hysteresis control mode. Outer ring uses normal voltage controller, inner ring uses current hysteresis control mode for filter capacitance, it use the quickness of hysteresis control and strong anti-interference ability to improve the characteristics of output voltage of the system. It can only limit capacitive current size, however, it can not control the load current and inductor current, such as the inverter output end of the overload current flows through the filter inductor caused by load or other reasons, and as for overcurrent protection of inverter power supply equipment, it is effective only by limiting the output filtering inductance current.

Therefore, In this paper it puts forward that it will combine the fuzzy control based on ant colony optimization with the inductance current instantaneous feedback technology, namely the compound control strategy, so that it can make the inverter power to get the ideal steady state, dynamic performance and good load adaptability.

\section{STUDY ON THE STRATEGY OF ANTI-IMPACT LOAD INVERTER POWER SUPPLY}

When inverter power supply is used in electronic equipment, the voltage stability, waveform distortion and reliability all have strict requirements, the reliability is especially important. It requires that it should not damage the equipment under the impact of the the load overload, transformer access, load short circuit, meanwhile it needs to withstand the extreme failure such as short-circuit for long time. However, due to the poor overload capacity of power semiconductor devices, when the load is connected with impact load such as the transformer, motor, it will cause the damage of the device. Therefore, when making access to impact load, protection is necessary. Considering from the supply aspect, it can use the following methods: a) increasing power capacity; b) increasing output impedance of the power, c) using current limiting circuit to limit the load current under the operating value of current feedback circuit. As the defects of the before two methods are obvious, so we only analyze the control strategy of the third method.

\subsection{Adding of the Current Inner Ring}

Adopting this method in constant voltage inverter power supply, the different load corresponds the different current waveform, so it can't use current instantaneous value as set value and it can only use the current average as the judgment standard of setting current loop and being into current loop. This will make the current loop response speed is slow, the current loop will need about one cycle delay, current needs to given 3-5 cycle delay. Such a long delay makes this kind of method for impact current has no inhibition effect). But through this way, voltage waveform obtained 
through current limiting will be better.

\subsection{Reducing the Output Voltage}

Method for reducing the voltage is that after detecting instantaneous output current is over, it will immediately pull the reference value of inverter voltage low thus to reduce the impact current, and then after delaying for a period of time, it will rises the voltage again. Because the detection results of circuit detection is instantaneous value of output current, circuit response will be fast, it can effectively protect the current from bad shocking. When impact is disappear, it can again return to normal output voltage .Though there are many defects, however, because the step-down value of circuit is well designed, delay time can be set in advance, in order to make it be adapt to the big impact, it must be set to be very low value. As far as mild overload is concerned, the protection is excessive. In the situation of large impact load, especially such as short circuit, impact will repeatedly pull lower voltage, so that it will happen shock accident which may cause to close down.

\subsection{Instantaneous Value Current Limiting Circuit}

Instantaneous current limiting circuit uses the characteristics that output current naturally decrease when inverter main circuit is in the stream state.when the peak of output current reaches the set current limited value, it immediately blocks the power switch conducting tube to force circuit into the fly-wheel state to make the output current reduced. When the current is reduced below a certain value of the current limit value, it removals the blocking signals to make the circuit control signal of the original to replay a role; if current is up to current limit value again, the above process is repeated, until the current no longer reach current limit value. The advantage of this circuit is that, when the load products the larger impact current, power always work will near the limit of their working current and as soon as impact of load current is below current limit value, the original control signals of the control system will work immediately, and recovery time is quite short.

Once the circuit design is completed, for different sizes of impact load and even if the output short circuit, it can effectively limit the output current and it won't stop; after the shock current attenuation or short-circuit point is disconnect by fuse, inverter power supply will be automatic returned to normal. But it also has defects, that is, when the inverter circuit, the output voltage will immediately be turned to a small value, the inverter is working under the voltage loop, after several cycles, due to the smaller feedback voltage, modulation ratio output by the voltage loop controller will come to limiting value. When inverter exits the short circuit state, current limiting circuit is no longer works and the modulation ratio is very large, so the output of the inverter power supply voltage will got a big impact. And because it is through the IGBT to limit current, when the current is in limitation, the distortion of inverter output voltage and current waveform are serious.

\subsection{Compound Control System}

As shown in Fig. (1), this article uses the compound control strategy of the fuzzy adaptive control combining with hysteresis control. The control method adopts the double closed-loop structure and takes fuzzy control based on ant colony optimization algorithm as a voltage outer ring, in order to improve the dynamic response of the output voltage. The inner ring is the current loop of hysteresis current limiting function, which can be used to improve the limitation on the instantaneous large current and thus to improve the adaptability of impact load.

When other parameters of fuzzy controller are set constant, the change of Ke can change the regulation effect of the system done by deviation e. When the ke is increasing, the increased rate of system will be faster, which could lead to the increase of overshoot amount of system, even cause oscillation or to make the system to be unstable; On the contrary, when ke is too small, which may cause the steady performance of the system and reduce the accuracy of system steady state. When the Kec is increasing, which is equivalent to the deviation change rate under the condition of invariable, it makes the ec value of input of fuzzy module to become larger, thus it increases the inhibition to the system state changes, thereby it can increase the stability of the system. Hence we can see that changing Kec can change regulation effect on the system produced by the deviation change rate of ec. Proportion module is looked as after the approximate reasoning, in the condition that the controller settings is invariant and the fuzzy subset number of the amount of coverage control is certain, the scaling factor ku is equivalent to increasing the total magnification of system. Increasing the ku will largely increase the response speed of system; ku is too small, which will make the increased rate of the system output be smaller, it cause the system steady-state accuracy be low. Quantization factor and scaling factor's have large influence on controlling performance. Their the self-tuning adaptive is one of the methods of 
adaptive fuzzy control using in real-time control. So in the article, it adopts the ant colony optimization algorithm to do self-adjusting and optimizing for proportion, quantitative factor.

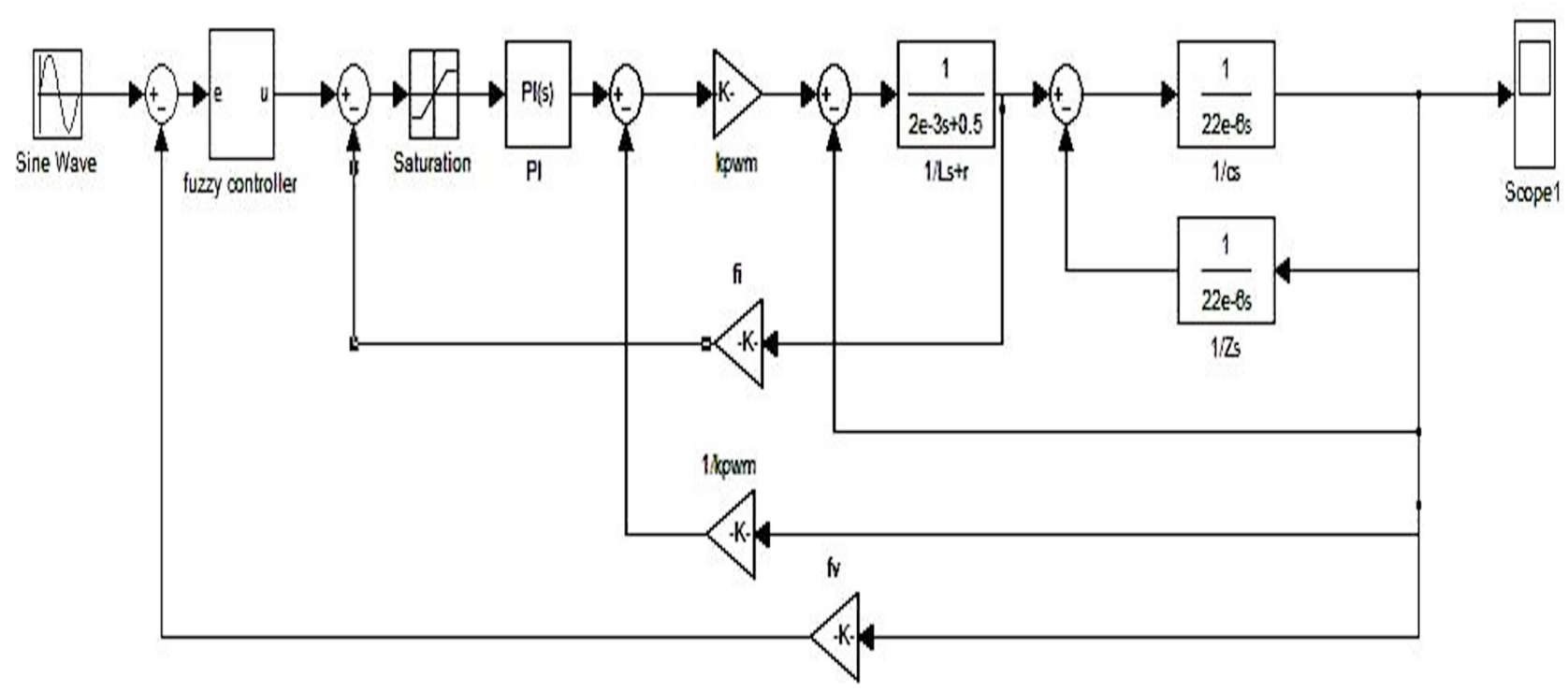

Fig. (1). Composite control method based on fuzzy-adaptive control and relay.

Increasing the value of $\mathrm{ku}$ will largely increase the response speed of system; When $\mathrm{Ku}$ is too small that the increased rate of the system output is smaller, which will make the system steady-state accuracy be worse. Quantization factor and scaling factor of ku have large influence on controlling performance, whose self-tuning adaptive are one of the means of adaptive fuzzy control applied to real-time control [10 - 12]. So in the this section it uses ant colony optimization algorithm to do self-adjustment optimization for proportion, quantification factor. It set up inference rules according to expert experience and the setting principle between e,ec and $u$; It establishes the proper fuzzy inference rules; fuzzy reasoning of fuzzy reasoning algorithm and the solution of fuzzy controller selects MAX-MIN synthesis method; Weighted average method is suitable for the case that membership function of the output fuzzy sets is symmetrical. It determines initialized quantification factor and the scaling factor, which are initialized by simulation. In the simulation, we can see that the error signal range comparing the output voltage feedback of inverter power supply which practically work is among [R-R]; If discourse domain of the input variable e, ec and the output variable $\mathrm{M}$ is respectively $[6,6],[6],[1,1]$, according to the range and discourse domain of e, ec and $\mathrm{M}$, it can get input variable of quantification factor e and ec, the scale factor of output variable E and EC. Ant colony optimization algorithm optimization quantification, the scaling factor based on ant colony algorithm which is introduced in front of the steps, in the Matlab platform we edit the ant colony optimization, do optimization automatically after setting the initial value.

\section{SIMULATION RESEARCH}

\subsection{Simulation Model}

It uses the simulation software Matlab to establish inverter power supply simulation model as shown in Fig. (2). The simulation parameters and indicators are as follows: $\mathrm{E}=400 \mathrm{~V}$ reprsents $\mathrm{DC}$ bus voltage; Output filter is $\mathrm{L}=0.43 \mathrm{mH}$, $\mathrm{C}=140 \mathrm{~F}, \mathrm{r}=0.1$, output voltage is $220 \mathrm{~V}$, frequency is $50 \mathrm{~Hz}$, rated load is 50 ; Rectifier load is Lo $=1 \mathrm{mH}, \mathrm{Co}=1000$ $\mathrm{F}, \mathrm{Ro}=50$, switch frequency and sampling frequency are all $10 \mathrm{KHz}$. In the Fig. (3), it shows the connection diagram of fuzzy controller and ant colony optimization program in Simulink.

\subsection{Output Simulation When Load Properties Being Different}

In the following, it simulates the system in No-load, resistive load, capacitive load, inductive load. In the Fig. (4), it shows the output voltage, current waveform diagram and phase voltage harmonic content changes of system. 
From output voltage and current waveform diagram of these two cases, we can see that the distortion degree of output voltage using the compound control method in this paper are smaller when the light, the load, the capacitive load resistance, inductive load, and output voltage and current wave-forms both have good sinusoidal characteristics;

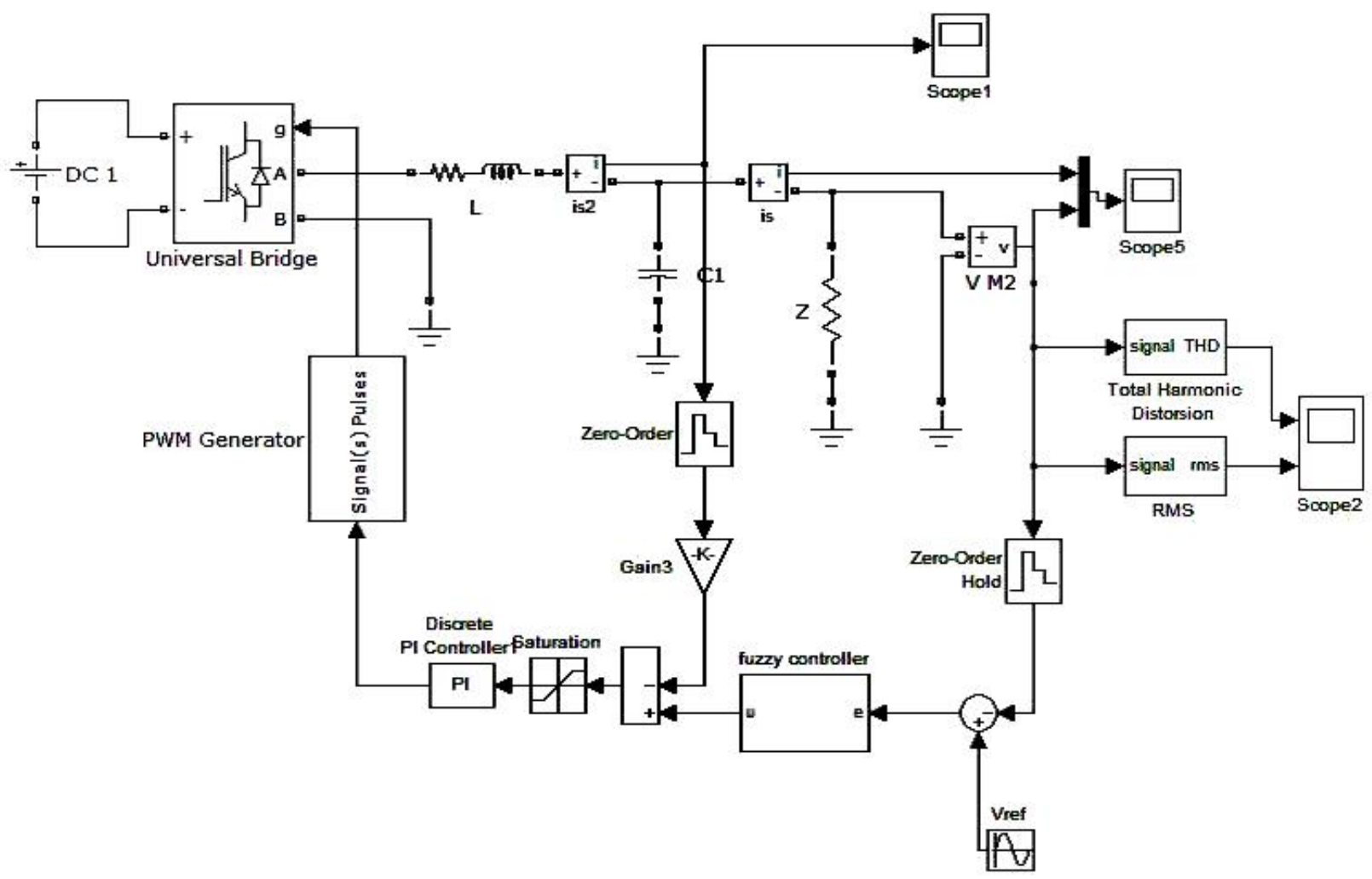

Fig. (2). Simulation model of inverter based on hybrid control method.

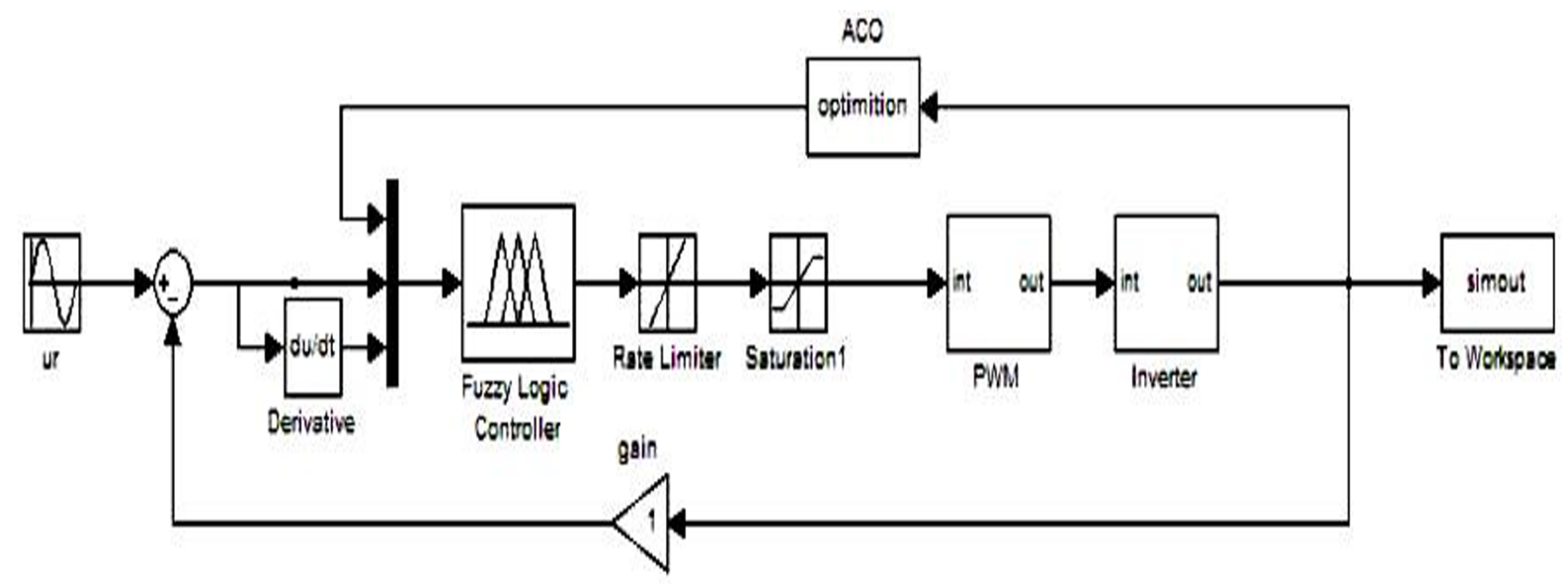

Fig. (3). Structure of fuzzy controller based on improved ACO algorithm. 
From harmonic content change curve of phase voltage in different condition of the load, you can see that harmonic content of the system output voltage is without too much change, it shows that the system has good control performance and the ability of system for harmonic suppression is stronger.

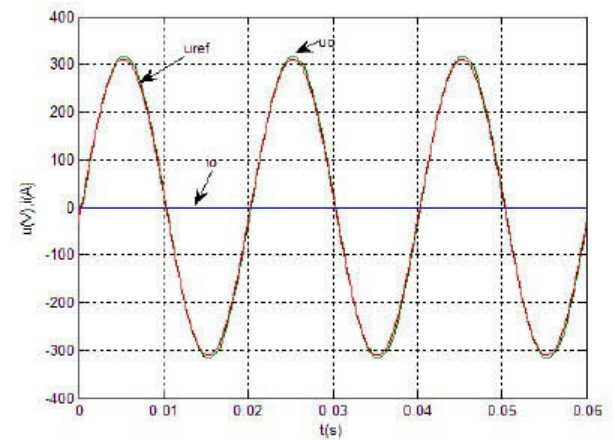

(a) Waveform of capacitive load
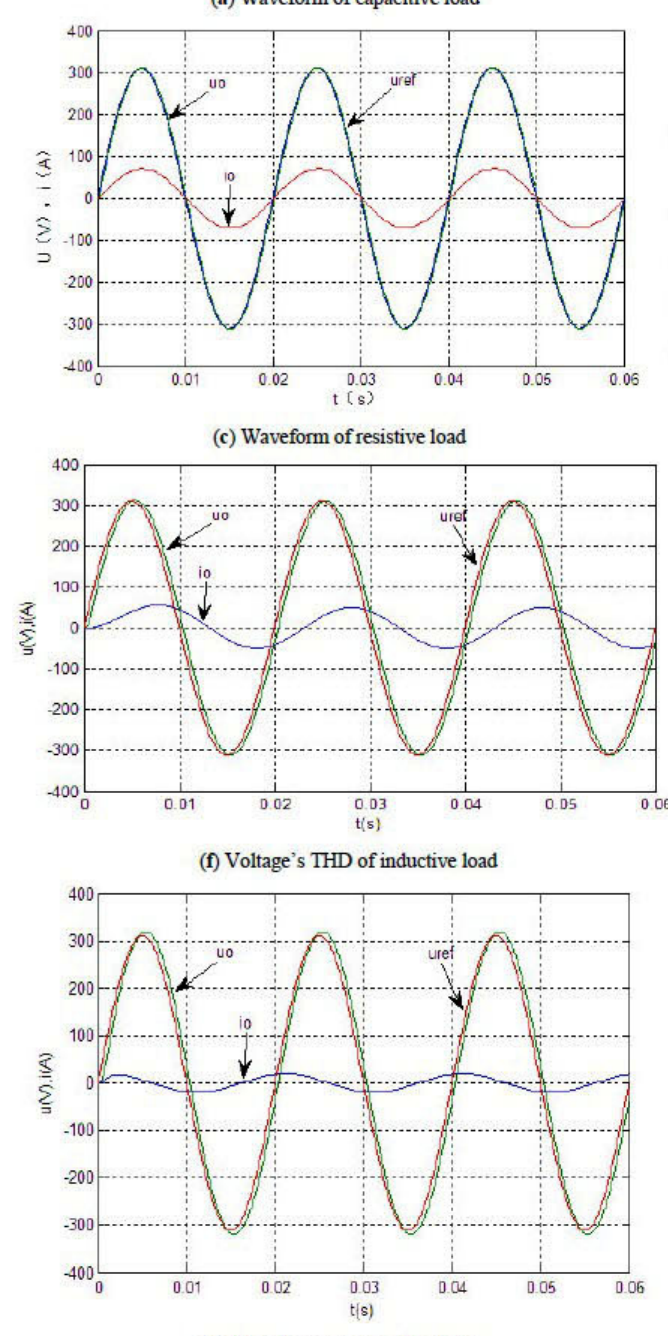

(g) Waveform of capacitive load
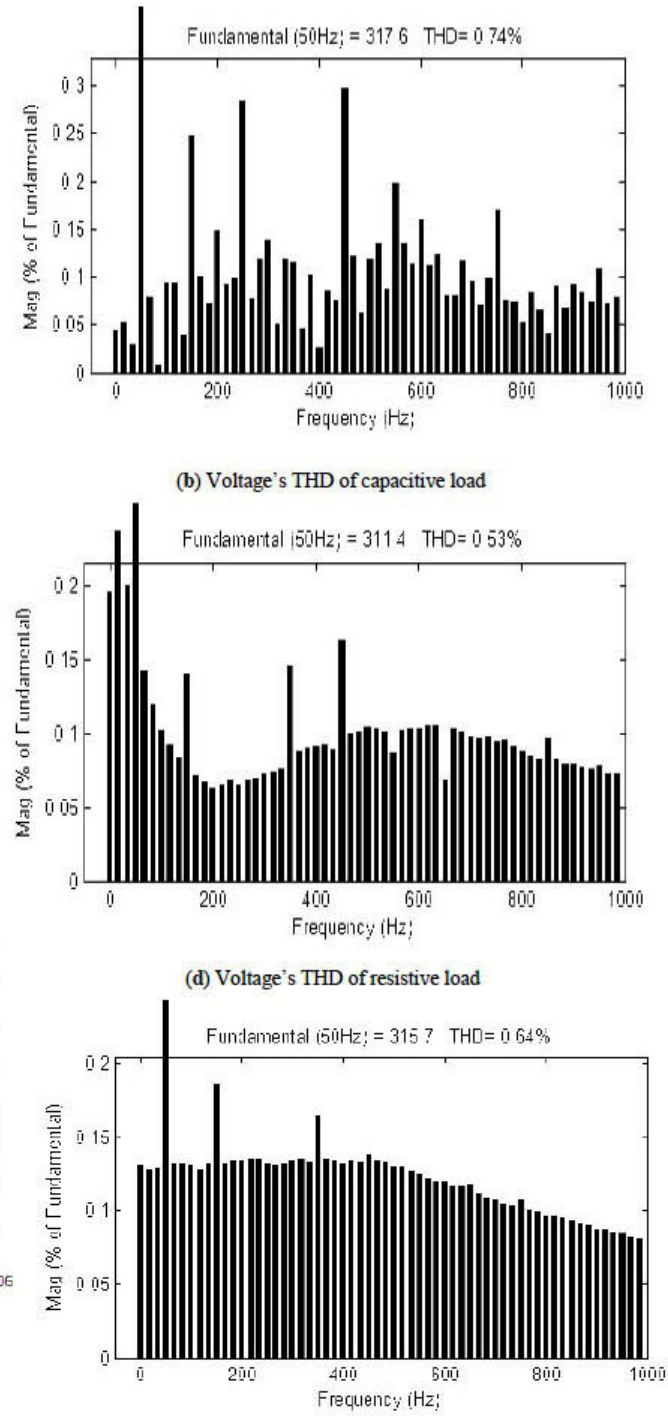

(e) Waveform of inductive load

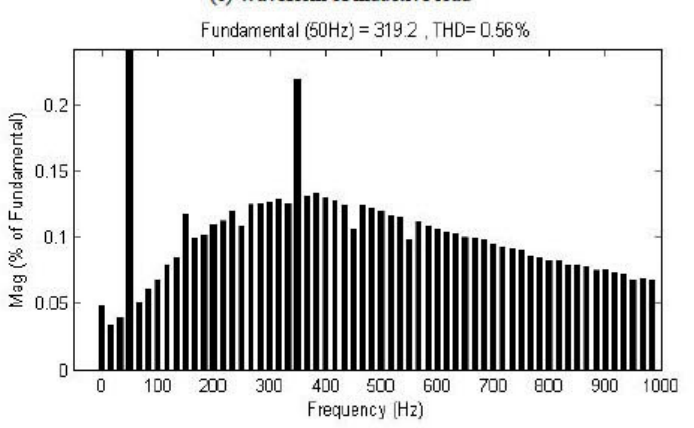

(h) Voltage's THD of capacitive load

Fig. (4). Output waveform of different load property.

\subsection{Simulation of System Dynamic}

In order to verify the dynamic characteristics of ant colony optimization of fuzzy control system, it does the 
simulation experiment of anticlimax, sudden load of the system, the experimental wave-forms are as shown in Fig. (5).

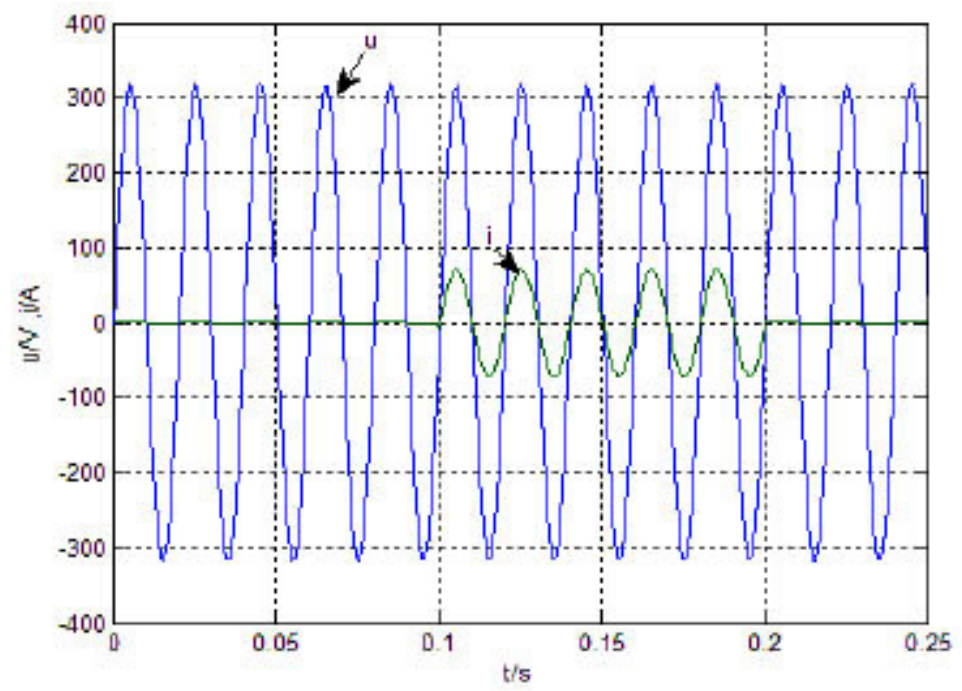

(a) Waveform of suddenly adding and removing

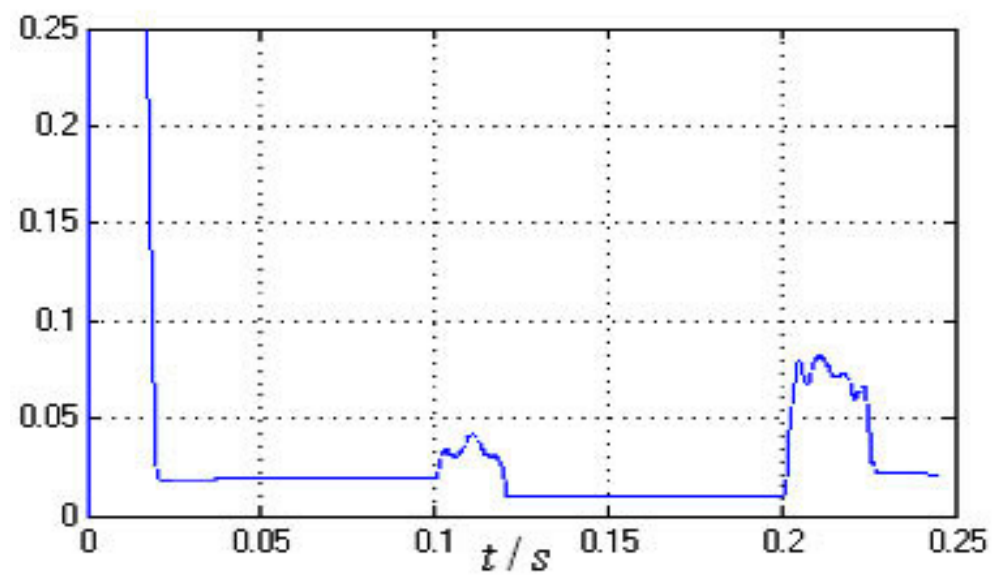

(b) Voltage's THD of suddenly adding and removing of load

Fig. (5). Waveform of the system's dynamic characteristics.

In the Fig. (4a), it shows the simulation waveform output of inverter when the sudden load, unload in system.

At $0.1 \mathrm{~s}$ part, inverter is studly added with impedance load, the output voltage will be dropped, the inductor current of output filtering turn large, inverter soon changes from the transient to steady state, the output voltage waveform turns smooth;

At $0.2 \mathrm{~s}$ part, inverter changes to no-load, then filtering inductance current will turns smaller, the inverter output voltage increases slightly, time of transient regulation turns shorter.

You can see he harmonic content of voltage changes in the process from Fig. (5b). Therefore, as mutation load, voltage wave-forms does not have too much change, fast and stability both meet the requirements, it indicates that the system has good dynamic response performance.

\subsection{The Analysis of Simulation Results}

Table 1 represents the parameters comparison of the waveform. The data in the Table 2 shows that under the impedance, sensibility, capacitive loads, double loop control and compound control system of the output voltage RMS are stable at around $220 \mathrm{~V}$, the voltage steady state error of them is less than $2 \%$, the composite control of harmonic content is low, thus it is visible that compound control can improve the performance index of inverter power system. 
Table 1. Output voltage of different control strategy in linear load state.

\begin{tabular}{|c|c|c|c|}
\hline Load & Voltage & Double circle control & Compound Control \\
\hline \multirow{3}{*}{ Impedance } & Output value of voltage $(\mathrm{V})$ & $218.7 \mathrm{~V}$ & $220.2 \mathrm{~V}$ \\
\cline { 2 - 4 } & Output voltage THD $(\%)$ & 0.85 & 0.53 \\
\hline \multirow{2}{*}{ Inductance } & Output Value of voltage (V) & $217.6 \mathrm{~V}$ & $223.2 \mathrm{~V}$ \\
\cline { 2 - 4 } & Output value of voltage THD(\%) (V) & 1.26 & 0.64 \\
\hline \multirow{2}{*}{ Capacitive } & Output voltage $(\mathrm{V})$ & $216.8 \mathrm{~V}$ & $223.7 \mathrm{~V}$ \\
\cline { 2 - 4 } & Output voltage THD(\%) & 1.33 & 0.56 \\
\hline
\end{tabular}

Table 2. Output voltage of different control strategy in rectifier load.

\begin{tabular}{|c|c|c|}
\hline Voltage & Double Circle Control & Compound Fuzzy Control \\
\hline Output value of voltage (V) & 213.7 & 224.1 \\
\hline Output value of voltage THD(\%) & 561 & 231 \\
\hline
\end{tabular}

Table 3 represents the parameters comparison of the waveform, when adding the rated load, the dynamic response time of double loop control system is $0.05 \mathrm{~s}$, and the composite control time of the dynamic response is around $0.02 \mathrm{~s}$. The output voltage peak value of double loop control system fell down $13 \mathrm{~V}$, the output voltage peak value of the compound control system only fell down $2.6 \mathrm{~V}$. This proved that double loop control system has the disadvantage of control instruction output delay, poor performance of the dynamic response). Therefore, the composite control can effectively improve the dynamic response performance of the system.

Table 3. Output voltage of different control strategy in suddenly adding load.

\begin{tabular}{|c|c|c|}
\hline Voltage & Double Circle Control & Compound Fuzzy Control \\
\hline Output value of voltage (V) & 218.7 & 219.2 \\
\hline Output value of voltage THD(\%) & 0.78 & 0.85 \\
\hline Dynamic response time (s) & 0.04 & 0.02 \\
\hline Instantaneous voltage drop (v) & 12 & 26 \\
\hline
\end{tabular}

To sum up, under the ceratin load, the double loop control and compound control, can both make the system output ideal waveform, so that the advantages of compound control was not obvious; But under nonlinear load (such as rectifier load), the output waveform of compound control system is better than double loop control system; in transient disturbance situation (such as sudden load), the output waveform of compound control system is better than double loop control system.

So the compound control complement can meet with each other very well, therefore, it also can meet the requirement of steady-state and dynamic performance of the system well.

\section{CONCLUSION}

In the paper, it proposes a hybrid control strategy of single-phase inverter, it makes combination of fuzzy control technology and the current instantaneous feedback control technology. Fuzzy control does not need accurate mathematical model of the controlled object, but it is based on its rich experience of expert and can make well control of nonlinear system, which can solve the problem that the load is uncertainty and load model are difficult to be established. Through ant colony optimization algorithm, the optimization of control parameters can be made thus solve the problem of fuzzy control dependence on expert experience. And current inner loop is added on the base of fuzzy voltage outer loop, through using current loop of rapid, anti-interference in time to effectively restrain the load disturbance, at the same time to join in the current inner ring current limiting link, it is able to solve the inverter power supply for impact load adaptability. This two kinds of control strategies are foster strengths and circumvent weaknesses, mutual penetration which can better meet the requirements of inverse frequency power supply for high quality output voltage.

Simulation results show that the composite control method introduced in the paper can be suitable for both dynamic and static characteristic of system, which has good control effect on different kinds of load. 


\section{CONFLICT OF INTEREST}

The author confirms that this article content has no conflict of interest.

\section{ACKNOWLEDGEMENTS}

Declared none.

\section{REFERENCES}

[1] P. Ning, Power System Impact Load Characteristic and Its Modeling Method Research.. North China Electric Power University: Beijing, 2006.

[2] D. Bing, Digital Pulse Inverter Welding Power Source Control Strategy and Application Research. Shandong University: Jinan, 2010.

[3] W. Zhu, and G. Liu, "Change the rules of fuzzy control and its application in resistance spot welding inverter type power supply", Electric Welding Machine, vol. 39, pp. 74-76, 2009.

[4] Y. Li, G. Yang, and L. Nianzhi, "Inverter Power Supply", Fuzzy PID Controller Detection and Control, vol. 31, pp. 35-38, 2009.3, vol. 31, pp. 35-38, 2009.

[5] H. Ting, Modular Three-Phase Inverter Power Supply Control And Protection Technology Research. Huazhong university of science and technology: Wuhan, 2007.

[6] Z. Wu, W. Ziyang, and Y. Wei, "Based on fuzzy self-tuning PI control and repetitive control single-phase sinusoidal pulse width modulation inverter power supply composite control method", Power Grid Technology, vol. 9, no. 14, pp. 30-34, 2005.

[7] Q. Ping, and Z. Ying, "The improved genetic algorithm for the optimization of fuzzy control and application", Journal of Automatic Control, vol. 1, no. 2, pp. 12-1, 2009

[8] H. Yong, "Fuzzy controller based on ant colony algorithm optimization study", Control Theory and Applications, vol. 26, no. 8, pp. 14-16, 2007.

[9] Z. Guang qi, H. Junan, W. Dong, and L. Chun-ling, Fuzzy Control Theory and Engineering Application. Huazhong university of science and technology press: Wuhan, 2006.

[10] M. Feil-ong, G. Qian-lang, W. Yong-ning, and Q. Chang-yuan, "Fuzzy control in the application of reactive power compensation", Journal of Northwest University (Natural Science Edition), vol. 40, no. 5, pp. 802-805, 2010.

[11] J.-P. Yu, C. Bing, H.-S. Yu, and J.-W. Gao, "Based on adaptive fuzzy the footwork of permanent magnet synchronous motor position tracking control", Control and Decision Making, vol. 10, pp. 1547-1551, 2010.

[12] C. F. Juang, and P. H. Chang, "Designing fuzzy-rule-based systems using ant colony optimization", IEEE Transactions on Fuzzy System, vol. 18, no. 1, pp. 138-149, 2010.

CRen Xian; Licensee Bentham Open.

This is an open access article licensed under the terms of the Creative Commons Attribution-Non-Commercial 4.0 International Public License (CC BY-NC 4.0) (https://creativecommons.org/licenses/by-nc/4.0/legalcode), which permits unrestricted, non-commercial use, distribution and reproduction in any medium, provided the work is properly cited. 